Journal Club

Editor's Note: These short, critical reviews of recent papers in the Journal, written exclusively by graduate students or postdoctoral fellows, are intended to summarize the important findings of the paper and provide additional insight and commentary. For more information on the format and purpose of the Journal Club, please see http://jneurosci.org/content/preparing-manuscript\#journalclub.

\title{
Balancing Dendrite Morphogenesis and Neuronal Migration during Cortical Development
}

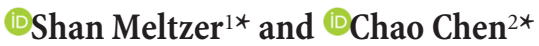 \\ ${ }^{1}$ University of California, San Francisco, Graduate Program in Neuroscience, San Francisco, California 94158, and ${ }^{2}$ Howard Hughes Medical Institute, \\ Departments of Physiology, Biochemistry and Biophysics, University of California, San Francisco, San Francisco, California 94158 \\ Review of Hoshiba et al.
}

Precisely controlled dendrite morphogenesis ensures proper neural circuit assembly and neural network integrity during development. In the cerebral cortex, dendrite morphogenesis usually starts after neuronal migration is complete. Insufficient dendritic branching has been observed in a variety of neurodevelopmental disorders, including autism and Rett syndrome (Arikkath, 2012). Much progress has been made to identify the molecular and cellular mechanisms that promote dendritic growth and branching (Jan and Jan, 2010; Dong et al., 2015). However, our knowledge of genes that restrain dendritic morphogenesis remains sparse, and our understanding of how this restraint is regulated in concert with migration remains to be elucidated.

One potential point of interaction between networks promoting and inhibiting dendrite growth is Sox11, a member of the Sox family of transcription factors that play diverse roles in neural development (Kamachi and Kondoh, 2013). Sox11 is essential for neuronal proliferation in sympathetic

Received July 29, 2016; revised Sept. 5, 2016; accepted Sept. 7, 2016.

S.M. was supported by National Science Foundation Graduate Research Fellowship Grant 1144247 and the American Association of University Women American Dissertation Fellowships. We thank Drs. Yuh-Nung Jan, Lily Jan, Gabriel McKinsey, and Kaela Singleton for providing feedback during the preparation of the manuscript.

The authors declare no competing financial interests.

*S.M. and C.C. contributed equally to this work.

Correspondence should be addressed to Shan Meltzer, University of California, San Francisco, 1550 4th Street, Room RH-490D, San Francisco, CA 94158. E-mail: shan.meltzer@ucsf.edu.

DOI:10.1523/JNEUROSCI.2425-16.2016

Copyright $\odot 2016$ the authors $\quad 0270-6474 / 16 / 3610726-03 \$ 15.00 / 0$ ganglia (Potzner et al., 2010), maintaining progenitor pools, and promoting neuronal differentiation (Chen et al., 2015, 2016). Mutations of Sox11 in humans causes Coffin-Siris syndrome, a congenital disorder characterized by intellectual disability, microcephaly, and other growth defects (Tsurusaki et al., 2014). Moreover, the expression of Sox11 dramatically decreases when dendritic morphogenesis is initiated after dorsal migration in the cerebral cortex (Allen Brain Atlas, http://www.brain-map.org/). Hence, Hoshiba et al. (2016) reasoned that Sox 11 is a strong candidate gene that may restrain dendritic morphogenesis during cortical development.

To investigate this hypothesis, the authors first examined the expression pattern of Sox11 proteins in the context of cortical development, when neurons migrate to their destinations in one of the six layers of the cortex. They found that the level of Sox11 proteins rapidly decreased after neurons entered the cortical plate. Importantly, they also observed that dendrite morphogenesis in neurons of layer 2/3 was initiated immediately following the decrease of Sox11 protein level, suggesting a link between the suppression of Sox 11 and the beginning of dendrite morphogenesis.

To determine whether Sox11 suppresses dendrite morphogenesis, the authors asked how reducing Sox 11 levels in layer $2 / 3$ neurons affected dendrite development in these neurons. They knocked down Sox11 during cortical development by introducing shRNA that specifically targeted Sox11. Compared with control neurons, neurons with reduced Sox 11 expression had more complex dendritic morphology after neuronal radial migration (postnatal day 1.5), supporting the hypothesis that Sox11 inhibits dendrite morphogenesis.

Because previous studies indicated that precocious branching of neurites causes radial migration defects in postmitotic neurons (Guerrier et al., 2009), the authors next investigated the effects of Sox11 knockdown on radial migration. As predicted, knocking down Sox11 in neurons at an earlier time point (embryonic day 15.5) resulted not only in more complex dendritic morphology, but also a severe radial migration defect, suggesting that constrained dendritic outgrowth is necessary for proper radial migration.

To test whether the reduction of Sox 11 expression is required for proper dendrite morphogenesis after migration, Hoshiba et al. (2016) investigated the consequences of prolonging Sox11 expression to a developmental stage when endogenous Sox11 was no longer detectable in the cortex. Interestingly, Sox11-overexpressing neurons displayed less complex dendrite morphology, with no changes in the expression of cortical layer markers. Together with the previous results, this experiment strongly suggests that downregulation of Sox11 is necessary for proper dendrite morphogenesis after radial migration is complete. 
Hoshiba et al. (2016) next investigated the mechanisms responsible for Sox 11 downregulation, asking whether the cessation of migration could trigger the reduction. Migrating neurons reach their destination by moving along radial glial cells via adhesion molecules, including $\mathrm{N}$-cadherin. Because loss of $\mathrm{N}$-cadherin function weakens the attachment between migrating neurons and radial glial fibers (Shikanai et al., 2011), the authors introduced dominant-negative $\mathrm{N}$-cadherin to block migration. Transfected cortical neurons that stopped in layer 5 had lower levels of Sox 11 than those of control layer $2 / 3$, suggesting that the end of migration causes the reduction of Sox 11 .

Hoshiba et al. (2016) have provided compelling in vivo evidence that Sox 11 inhibits dendrite morphogenesis to allow proper radial migration during cortical development (Fig. 1). How Sox 11 inhibits dendritic growth warrants further investigation. There are two nonmutually exclusive mechanisms whereby Sox11 may inhibit dendrite morphogenesis and promote migration. First, Sox11 may drive the expression of known signaling proteins that inhibit dendrite outgrowth in known signaling pathways, such as SlitlaRobo2 signaling (Campbell et al., 2007), Notch signaling (Dong et al., 2015), p35 (Gupta et al., 2003), Cdk5 (Ohshima et al., 2007), and chondroitin sulfate proteoglycans (Coles et al., 2011). Second, Sox11 may inhibit the expression of genes that promote dendrite morphogenesis. For example, Lis1, a protein that regulates the microtubule motor protein dynein, is required for both neuronal migration and dendrite arborization (Vallee and Tsai, 2006), and is upregulated in the absence of Sox11 in the cerebral cortex (Wang et al., 2013). It would be informative to test whether the increase of Lis 1 expression is required for promoting dendrite outgrowth after the disappearance of Sox 11 during cortical development. To get a more comprehensive view of the downstream components of Sox11, a comparison of the gene expression profiles of control neurons and neurons transfected with Sox11-shRNA might provide useful data and reveal novel regulators of dendrite morphogenesis. Chromatin immunoprecipitation studies would also help to define the genomic binding sites of Sox 11 and may further narrow the list of candidate target genes. No matter which genes are found downstream of Sox11, it would be important to tease apart the roles of Sox11 downstream components in promoting migration and inhibiting dendrite

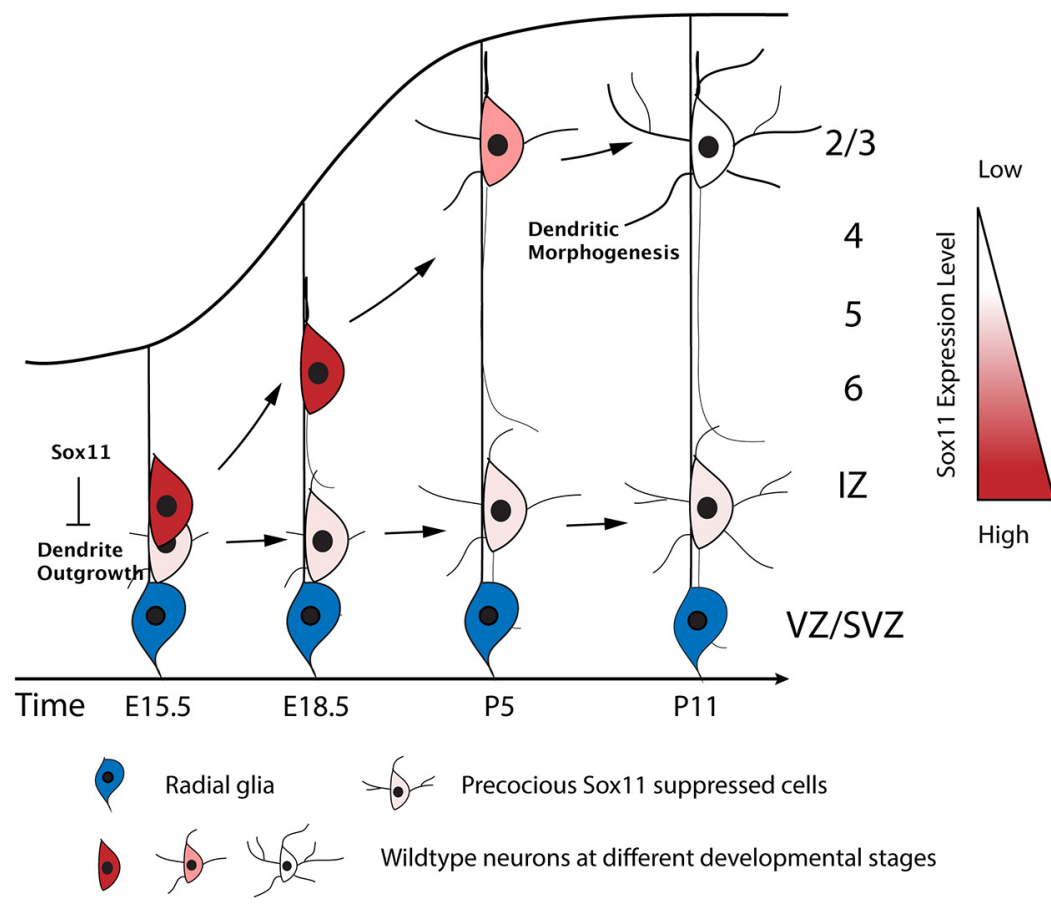

Figure 1. A summary of the findings of Hoshiba et al. (2016). High expression of Sox11 in newly born neurons inhibits dendritic morphogenesis and promotes migration into the cortical plate in the cerebral cortex. The authors propose that the end of migration triggers the reduction of Sox11, thereby allowing dendrite morphogenesis. Precocious suppression of Sox 11 expression leads to migration defects as well as increases in dendritic growth. This suggests that Sox11 controls the balance between dendrite morphogenesis and migration during development. VZ, Ventricular Zone; SVZ, subventricular zone; IZ, intermediate zone.

morphogenesis, as these two functions may require separate cellular machinery.

This study also improves our understanding of the function of Sox11 during cortical development, as it was thought that Sox11 acts redundantly with Sox4, another member of the SoxC transcription factor family, during cortical development. A previous study (Shim et al., 2012) found that conditional knock-out of Sox1 1 with Emx1-Cre active by embryonic day 9.5 did not lead to any changes in the distribution of markers for the superficial (Cux1) and deep (Ctip2) layer in the somatosensory-motor cortex, whereas Hoshiba et al. (2016) only looked at the somatosensory cortex. However, a severe migration defect was observed in Sox4 and Sox11 double knock-out mutants, suggesting that Sox 4 can compensate for the loss of Sox11 (Shim et al., 2012). Instead of using conditional knock-out, Hoshiba et al. (2016) studied the role of Sox11 using knockdown, but it is unclear exactly how efficient the knockdown was. These seemingly contradictory results may also be attributable to fact that Sox 11 was removed at different times, or to differences in the remaining level of Sox 11 expression in these two studies, as knockdown usually does not reduce expression levels as much as knock-out. Examining the consequences of conditionally knocking out (rather than knocking down) Sox11, on dendrite morphogenesis might address the different results observed in these studies.

Hoshiba et al. (2016) proposed that the end of migration triggers the reduction of Sox 11, based on their finding that the level of Sox 11 expression was reduced in layer 5 cells transfected with dominant-negative $\mathrm{N}$-cadherin, compared with those of control layer $2 / 3$ cells. However, there are two alternate explanations of this result. First, the local signaling environment, instead of the end of migration, might induce the reduction of Sox11 in the neurons that stopped migrating in layer 5. It is important to note that the expression level of Sox11 in deep layers is already significantly lower than that in layer $2 / 3$ at the time of examination (Hoshiba et al., 2016, their Fig. 2 B). Second, N-cadherin signaling itself may promote the expression of Sox11 in addition to its role in facilitating migration. In this case, lower level of Sox11 in neurons may be a result of reduced $\mathrm{N}$-cadherin signaling, rather than the end of migration. It would be informative to determine whether the level of $\mathrm{N}$-cadherin proteins is reduced after migration. A comparison of the levels of Sox 11 proteins in control layer $2 / 3$ 
neurons and neurons overexpressing $\mathrm{N}$-cadherin may also help to address this possibility. If $\mathrm{N}$-cadherin signaling is indeed upstream of Sox11, the neurons overexpressing $\mathrm{N}$-cadherin will have prolonged Sox11 expression after migration. Excluding these two alternative possibilities is necessary to solidify the conclusion that end of radial migration triggers the decrease of Sox11.

Are there other regulators that may trigger the reduction of Sox11? Little is known about how the expression level of Sox11 is regulated during neural development. Previous studies indicate that Sox11 expression is sensitive to promoter methylation, the level of which changes as development progresses in the mouse brain (Pamnani et al., 2016). In cultured rat cortical neurons, Sox11 is also regulated by microRNAs, which post-transcriptionally fine-tune the expression of their target genes (Haenisch et al., 2015). Hence, it would be of great interest to examine whether dynamic DNA methylation or post-transcriptional modification could regulate the Sox11 expression level in vivo during cortical development.

In conclusion, the study presented by Hoshiba et al. (2016) shows that Sox11 inhibits dendritic morphogenesis of excitatory neurons, thus facilitating their migration during cortical development. This work opens new doors for future investigations of the molecular mechanisms underlying the balance between dendrite morphogenesis and migration. This study makes an important contribution to our basic understanding of how neurons balance morphogenesis and other developmental processes.

\section{References}

Arikkath J (2012) Molecular mechanisms of dendrite morphogenesis. Front Cell Neurosci 6:61. CrossRef Medline

Campbell DS, Stringham SA, Timm A, Xiao T, Law
MY, Baier H, Nonet ML, Chien CB (2007) Slitla inhibits retinal ganglion cell arborization and synaptogenesis via Robo2-dependent and -independent pathways. Neuron 55:231-245. CrossRef Medline

Chen C, Lee GA, Pourmorady A, Sock E, Donoghue MJ (2015) Orchestration of neuronal differentiation and progenitor pool expansion in the developing cortex by SoxC genes. J Neurosci 35:10629-10642. CrossRef Medline

Chen C, Jin J, Lee GA, Silva E, Donoghue M (2016) Cross-species functional analyses reveal shared and separate roles for Sox11 in frog primary neurogenesis and mouse cortical neuronal differentiation. Biol Open 5:409417. CrossRef Medline

Coles CH, Shen Y, Tenney AP, Siebold C, Sutton GC, Lu W, Gallagher JT, Jones EY, Flanagan JG, Aricescu AR (2011) Proteoglycan-specific molecular switch for RPTP $\sigma$ clustering and neuronal extension. Science 332:484-488. CrossRef Medline

Dong X, Shen K, Bülow HE (2015) Intrinsic and extrinsic mechanisms of dendritic morphogenesis. Annu Rev Physiol 77:271-300. CrossRef Medline

Guerrier S, Coutinho-Budd J, Sassa T, Gresset A, Jordan NV, Chen K, Jin WL, Frost A, Polleux F (2009) The F-BAR domain of srGAP2 induces membrane protrusions required for neuronal migration and morphogenesis. Cell 138:990-1004. CrossRef Medline

Gupta A, Sanada K, Miyamoto DT, Rovelstad S, Nadarajah B, Pearlman AL, Brunstrom J, Tsai LH (2003) Layering defect in p35 deficiency is linked to improper neuronal-glial interaction in radial migration. Nat Neurosci 6:1284-1291. CrossRef Medline

Haenisch S, Zhao Y, Chhibber A, Kaiboriboon K, Do LV, Vogelgesang S, Barbaro NM, Alldredge BK, Lowenstein DH, Cascorbi I, Kroetz DL (2015) SOX11 identified by target gene evaluation of miRNAs differentially expressed in focal and non-focal brain tissue of therapy-resistant epilepsy patients. Neurobiol Dis 77:127-140. CrossRef Medline

Hoshiba Y, Toda T, Ebisu H, Wakimoto M, Yanagi S, Kawasaki H (2016) Sox11 balances dendritic morphogenesis with neuronal migration in the developing cerebral cortex. J Neurosci 36:5775-5784. CrossRef Medline Jan YN, Jan LY (2010) Branching out: mecha- nisms of dendritic arborization. Nat Rev Neurosci 11:316-328. CrossRef Medline

Kamachi Y, Kondoh H (2013) Sox proteins: regulators of cell fate specification and differentiation. Development 140:4129-4144. CrossRef Medline

Ohshima T, Hirasawa M, Tabata H, Mutoh T, Adachi T, Suzuki H, Saruta K, Iwasato T, Itohara S, Hashimoto M, Nakajima K, Ogawa M, Kulkarni AB, Mikoshiba K (2007) Cdk5 is required for multipolar-to-bipolar transition during radial neuronal migration and proper dendrite development of pyramidal neurons in the cerebral cortex. Development 134: 2273-2282. CrossRef Medline

Pamnani M, Sinha P, Singh A, Nara S, Sachan M (2016) Methylation of the Sox 9 and Oct4 promoters and its correlation with gene expression during testicular development in the laboratory mouse. Genet Mol Biol 39:452458. CrossRef Medline

Potzner MR, Tsarovina K, Binder E, PenzoMéndez A, Lefebvre V, Rohrer H, Wegner M, Sock E (2010) Sequential requirement of Sox 4 and Sox 11 during development of the sympathetic nervous system. Development 137:775-784. CrossRef Medline

Shikanai M, Nakajima K, Kawauchi T (2011) $\mathrm{N}$-cadherin regulates radial glial fiberdependent migration of cortical locomoting neurons. Commun Integr Biol 4:326-330. CrossRef Medline

Shim S, Kwan KY, Li M, Lefebvre V, Sestan N (2012) Cis-regulatory control of corticospinal system development and evolution. $\mathrm{Na}$ ture 486:74-79. CrossRef Medline

Tsurusaki Y, Koshimizu E, Ohashi H, Phadke S, Kou I, Shiina M, Suzuki T, Okamoto N, Imamura S, Yamashita M, Watanabe S, Yoshiura K, Kodera $\mathrm{H}$, Miyatake S, Nakashima M, Saitsu H, Ogata K, Ikegawa S, Miyake N, Matsumoto N (2014) De novo SOX11 mutations cause Coffin-Siris syndrome. Nat Commun 5:4011. CrossRef Medline

Vallee RB, Tsai JW (2006) The cellular roles of the lissencephaly gene LIS1, and what they tell us about brain development. Genes Dev 20: 1384-1393. CrossRef Medline

Wang Y, Lin L, Lai H, Parada LF, Lei L (2013) Transcription factor Sox11 is essential for both embryonic and adult neurogenesis. Dev Dyn 242:638-653. CrossRef Medline 